\title{
Pengaruh Persepsi dan Motivasi Wisatawan Terhadap Minat Kunjung Ulang Di Pantai Baru Yogyakarta
}

\author{
Suhartapa ${ }^{1)}$, Agung Sulistyo ${ }^{2)}$ \\ Pariwisata, Sekolah Tinggi Pariwisata Ambarrukmo 1,2) \\ Jl. Ahmad Yani Ring Road Timur Banguntapan Bantul Yogyakarta \\ E-mail: suhartopomm@gmail.com,
}

\begin{abstract}
Abstrak
Minat kunjung ulang wisatawan adalah bagian dari perilaku wisatawan yang merupakan dorongan wisatawan untuk melakukan kunjungan lagi di destinasi wisata yang sama. Faktor yang bisa mempengaruhi minat kunjung ulang diantaranya adalah persepsi wisatawan terhadap daya tarik objek wisata dan motivasi wisatawan untuk melakukan kunjung ulang. Penelitian ini dimaksudkan untuk mengetahui pengaruh persepsi dan motivasi wisatawan terhadap daya tarik wisata terhadap minat kunjung ulang di Pantai Baru Bantul Yogyakarta. Rumusan masalah penelitian adalah: 1). Apakah persepsi wisatawan tentang daya tarik objek wisata dan motivasi wisatawan secara bersama-sama mempengaruhi minat kunjung ulang wisatawan; 2). Apakah persepsi wisatawan tentang daya tarik suatu objek wisata mempunyai pengaruh terhadap minat kunjung ulang wisatawan; dan 3). Apakah motivasi wisatawan mempunyai pengaruh terhadap minat kunjung ulang wisatawan. Metode pengambilan sampel yang digunakan adalah nonprobability sampling dengan jumlah sampel sebanyak 100 responden. Alat analisis yang digunakan dalam penelitian ini adalah analisis regresi berganda. Hasil penelitian ini menunjukkan: 1) persepsi wisatawan pada daya tarik objek wisata dan motivasi wisatawan secara bersama-sama mempunyai pengaruh terhadap minat kunjung ulang wisatawan; 2) persepsi wisatawan tentang daya tarik suatu objek wisata mempunyai pengaruh positif terhadap minat kunjung ulang wisatawan; dan 3) motivasi wisatawan mempunyai pengaruh positif terhadap minat wisatawan untuk melakukan kunjung ulang.
\end{abstract}

Kata Kunci: Persepsi, Motivasi, dan Minat Kunjung Ulang

The Influence of Tourist's Perceptions and Motivations on The Interest of Repeat Visits at Pantai Baru Yogyakarta

\begin{abstract}
The interest of returning tourist is part of tourist behavior which is an incentive for tourist to make another visit to the same tourist destination. Factors that can affect the interest in repeat visits include tourists perceptions of the attractiveness of tourist objects and the motivation of tourists to make repeat visits. This research was conducted to determine the effect of perceptions and motivation of tuorists on tourist attractiveness towards revisiting interest in Pantai Baru Bantul Yogyakarta. The formulations of the research problems are: 1). Do tourists perceptions of the attractiveness of a tourist attraction and tourist motivation together influence the interest in visiting tourists' re-visits 2). Does the perception of tourists about the attractiveness of a tourist object have an influence on the interest in visiting tourist again; and 3). Does tourist motivation have an influence on the interest in visiting tourists again? The sampling method used was nonprobability sampling with a sample size of 100 respondents. The analytical tool used in this research is multiple regression analysis. The results of this study indicate: 1) the perception of tourists on the attractiveness of tourist objects and the motivation of tourists together have an influence on the interest in visiting tourists again; 2) the perception of tourists about the attractiveness of a tourist abject has a positive influence on the interest in returning tourists; and 3) tourist motivation has a positive influence on tourist interest in revisiting.
\end{abstract}

Keywords: Perception, Motivation, and Revisiting Interest 


\section{PENDAHULUAN}

Dewasa ini pariwisata adalah merupakan sektor di bidang perekonomian yang diunggulkan karena mempunyai kontribusi cukup signifikan terhadap penerimaan negara sehingga harus ditingkatkan dan dikembangkan peranannya. Dalam Undang-Undang Tahun 2009 tentang kepariwisataan ditekankan bahwa perlu peningkatan pembangunan bidang pariwisata dengan tujuan memperluas kesempatan kerja dan peluang usaha, meningkatkan penerimaan devisa, dan memperkenalkan alam dan budaya Indonesia.

Daerah Istimewa Yogyakarta salah satu propinsi yang kaya akan tempat wisata dengan memiliki keunikan masing-masing yang mempunyai potensi untuk disuguhkan pada para wisatawan. Menurut data tahun 2019 Daerah Istimewa Yogyakarta memiliki sejumlah obyek wisata mulai dari obyek wisata alam, wisata budaya, wisata buatan serta memiliki 185 desa/kampung wisata (Statistik Kepariwisataan Daerah Istimewa Yogyakarta 2019). Dari lima kabupaten/kota di propinsi ini terdapat tiga kabupaten yang mempunyai keindahan alam luar biasa khususnya keindahan pantai lautnya, yaitu kabupaten Bantul, Kulon Progo dan Gunung Kidul. Salah satu destinasi wisata di Kabupaten Bantul yang berupa pantai adalah Pantai Baru.

Pantai Baru mulai diresmikan sebagai obyek wisata sejak tahun 2010 dan merupakan pantai paling muda di Bantul Yogyakarta. Pantai ini berlokasi di Dusun Ngentak, Desa Poncosari, Kecamatan Srandakan, Kabupaten Bantul ini memiliki luas area empat kilometer dengan pasir hitam disepanjang pantai. Salah satu keunggulan yang dimiliki pantai Baru adalah adanya ribuan kincir angin yang berdiri kokoh disebelah barat pantai. Adanya ribuan kincir angin dapat menambah keunikan tersendiri dibandingkan pantai lainnya. Disamping itu kelebihan pantai Baru adalah tempatnya yang teduh dengan adanya tanaman pohon cemara laut disepanjang bibir pantai.

Wisatawan yang menjalankan kegiatan perjalanan wisata merupakan salah satu dari stakeholder yang mempunyai peran cukup besar dalam pariwisata. Menurut Pitana (2005), ada beberapa faktor yang bisa mempengaruhi seorang wisatawan dalam melakukan wisata ataupun menetapkan untuk melakukan wisata, baik faktor bersifat internal maupun faktor eksternal. Seseorang melakukan wisata adalah guna memenuhi kebutuhannya mencari sesuatu pengalaman (experience) yang belum pernah didapatkan sebelumnya. Oleh karena itu usaha pengelola wisata dalam mengembangkan daya tarik destinasi wisata harus diarahkan pada semua faktor yang dapat mempengaruhi para pelaku wisata.

Pelaku pariwisata baik pengelola destinasi wisata, pengusaha industri pariwisata termasuk pemerintah harus bisa membuat kebijakan dan keputusan dalam rangka memenuhi harapan serta kebutuhan dan keinginan wisatawan. Beberapa pendekatan yang bisa dijalankan yaitu dengan pendekatan market driven maupun product driven. Pendekatan market driven merupakan strategi pemasaran yang dilandasi pemahaman mengenai selera dan keinginan pasar wisatawan, sedangkan pendekatan product driven adalah strategi pemasaran yang lebih berorientasi pada produk.

Zaenuri (2012) berpendapat bahwa daya tarik wisata yang didukung dengan fasilitas dan pelayanan yang baik dapat meningkatkan minat dan loyalitas wisatawan. Daya tarik wisata dan pelayanan merupakan inti dari kegiatan pariwisata yang berperan sebagai pendorong bagi calon wisatawan dalam menjalankan kegiatan wisata. Apabila para pelaku kegiatan pariwisata dapat menyediakan destinasi wisata yang menarik dan memberikan pelayanan yang baik kepada wisatawan yang berkunjung maka akan berdampak pada kegiatan wisata yang dilakukannya, khususnya pengaruh minat bagi wisatawan tersebut untuk berkunjung kembali.

Pengembangan usaha pariwisata di dinilai baik apabila pengelolaan daya tarik wisata dapat dilakukan secara tepat baik dalam hal pelayanan, sarana dan prasarana serta aksesibilitas dan informasi yang baik guna memenuhi kebutuhan wisatawan. Apabila wisatawan mempunyai persepsi baik pada destinasi wisata yang dikunjunginya maka dapat mempengaruhi minat wisatawan tersebut untuk 
berkunjung lagi. Menurut Umar (2003), minat kunjung ulang sebagai perilaku yang terjadi akibat respon seseorang terhadap suatu objek yang dinunjukkan oleh keinginan pelanggan untuk berkunjung kembali.

\section{TINJAUAN LITERATUR}

\section{Pengertian Persepsi}

Persepsi merupakan suatu proses yang diawali dengan penginderaan, yaitu suatu proses yang diterima oleh seseorang melalui alat inderanya. Proses penginderaan tersebut tidak bisa lepas dari proses persepsi dimana alat indera disini sebagai penghubung antara seorang individu dengan dunia luar. Menurut Stanton, persepsi adalah makna yang mesti dikaitkan berdasarkan pengalaman yang pernah dirasakan, rangsangan (stimuli) yang kita daptkan lewat panca indera. Sedangkan menurut Hawkins dan Coney, persepsi adalah proses bagaimana rangsangan itu dipilih, diatur dan diinterprestasikan (dalam Sangaji dan Sopiah, 2013).

Proses persepsi meliputi pemilihan, pengorganisasian dan interprestasi (Sangaji dan Sopiah, 2013:69). Pemilihan persepsi akan muncul ketika seseorang menerima dan menyeleksi stimulus yang didasarkan pada set psikologis (psychological set) yang dipunyai. Organisasi perseptual (perceptual organization) mempunyai arti seseorang mengelompokkan berbagai informasi agar diperoleh pengertian yang komprehensif sehingga dapat dipahami secara jelas dan akan melakukan tindakan berdasarkan pemahamannya itu. Interprestasi perseptual adalah menginterprestasikan rangsangan (stimuli) yang diterima oleh seseorang atas dasar pengalaman sebelumnya yang tersimpan dalam memorinya. Sekelompok orang atau wisatawan bisa mempunyai persepsi melalui pengukuran terhadap kejelasan objek yang didasarkan pada dua hal, yaitu persepsi fisik dan persepsi non fisik (Cahya Mutri dan Sujali dalam Witarsana, 2017).

\section{Daya Tarik Wisata}

Menurut Undang-Undang Republik Indonesia No. 10 Tahun 2009 dalam Gusti Bagus Arjana (2016: 7), daya tarik wisata adalah segala sesuatu yang unik, nyaman, dan nilai yang berupa keanekaragaman sumber daya alam, budaya, dan hasil buatan manusia yang menjadi sarana kunjungan wisatawan. Objek dan daya tarik wisata merupakan formasi dan fasilitas terkait, yang bisa menarik wisatawan untuk mengunjungi di suatu tempat tertentu.

\section{Motivasi}

Motivasi dapat disebut sebagai sebuah alasan yang melatarbelakangi adanya perbuatan yang dilakukan oleh seseorang. Motivasi merupakan suatu dorongan yang ada pada diri seseorang dalam bertindak atau sesuatu yang mendasari seseorang melakukan perbuatan tertentu. Motivasi perjalanan bisa dilihat berdasarkan kelompok motivasi, sifat motivasi perjalanan, dan dimensi motivasinya. Menurut Mclntosh (dalam Hayati, 2012), motivasi bisa dikelompokkan menjadi empat yaitu physiological motivation (motivasi yang bersifat fisik), cultural motivation (motivasi budaya), social motivation (motivasi yang bersifat social), dan fantasy motivation (motivasi karena fantasi). Berdasarkan sifat motivasi perjalanan motivasi bisa dikelompokkan menjadi dua yaitu movasi intrinsik dan ekstrinsik. Motivasi intrinsik adalah motiv yang sudah ada pada dirinya untuk melakukan sesuatu, sehingga motif ini tidak perlu dorongan dari luar. Sedangkan motivasi ekstrinsik merupakan tindakan yang dilakukan karena ada dorongan dari luar individu. Apabila dilihat berdasarkan dimensi motivasinya, dapat dibedakan menjadi motivasi yang mendorong dan motivasi yang menarik seseorang dalam untuk menjalankan perjalanan wisata. (Witarsana, 2016).

\section{Minat Kunjung Ulang}

Menurut Shandily, minat adalah kecenderungan berperilaku secara terarah terhadap kegiatan objek atau pengalaman tertentu (Shandily dalam Nuraeni, 2014). Minat kunjung ulang merupakan keinginan yang kuat dari pengunjung untuk 
mengulang berkunjung kembali sebagai respon langsung pasca kunjungannya di waktu lampau. Minat berkunjung seseorang dipengaruhi motivasi dan minat pada suatu objek wisata, suhingga minat berkunjung merupakan suatu pernyataan tentang keinginan seseorang untuk membeli suatu barang atau jasa.

Teori minat beli ulang bisa dipakai sebagai referensi dalam membahas minat kunjung ulang. Minat beli ulang adalah sebuah dorongan seorang konsumen untuk melakukan pembelian ulang. Dengan demikian minat kunjung ulang adalah suatu dorongan seseorang untuk kembali mengunjungi tempat yang memiliki daya tarik bagi dirinya. Menurut Nuraeni (2014) dalam penelitiannya yang berjudul Analisis Faktor-faktor yang Mempengaruhi Minat Kunjungan Ulang Wisatawan Wisatawan Museum Ranggawarsita Semarang, menyimpulkan bahwa faktor-faktor yang bisa berpengaruh terhadap minat untuk berkunjung lagi ke suatu destinasi adalah kepuasan saat melakukan kunjungan, ada motivasi tertentu, kecintaan pada destinasi, dan proses informasi terhadap destinasi tersebut. Jika wisatawan merasa puas, mereka akan berkunjung kembali di lain waktu dan akan menginformasikan kepada orang lain terhadap pengalaman yang dirasakan selama melakukan kunjungan.

\section{METODE, DATA DAN ANALISIS}

Populasinya dalam penelitian ini adalah pengunjung Pantai Baru yang berlokasi di dusun Ngentak, Poncosari, Srandakan, Bantul, Daerah istimewa Yogyakarta. Dalam melakukan pengambilan sampel penelitian ini metode yang digunakan adalah nonprobability sampling dan convenience sampling. Jumlah sampel yang digunakan sebanyak 100 responden. Kuesioner penelitian dibuat dengan kategori pilihan ganda (multiple choice) menggunakan skala likert dengan metode penilaian (skoring) mulai dari sangat tidak setuju (1) sampai sangat setuju (5).

Alat analisa yang digunakan adalah analisis regresi linier berganda, sebelumnya dilakukan Uji Asumsi klasik terlebih dahulu yaitu dengan Uji Multikolinearitas, Uji Heteroskedastisitas, dan Uji Normalitas. Analisis regresi linear berganda adalah analisa untuk mengukur pengaruh antara lebih dari satu variabel bebas atau lebih terhadap variabel terikat, atau untuk meramalkan dua variabel bebas atau lebih terhadap variabel terikat, yang dirumuskan sebagai berikut :

$Y=a+b_{1} X_{1}+b_{2} X_{2}$

Dimana: $Y=$ Minat kunjung ulang

$$
\begin{aligned}
\mathrm{a}= & \text { Konstanta } \\
\mathrm{X}_{1}= & \text { Persepsi wisatawan pada } \\
& \text { daya tarik objek wisata } \\
\mathrm{X}_{2}= & \text { Motivasi wisatawan } \\
b_{1} b_{2}= & \text { angka koefisien regresi }
\end{aligned}
$$

Selanjutnya dilakukan uji $t$ untuk mengetahui seberapa banyak pengaruh satu variabel independen secara parsial terhadap variabel dependen. Uji $F$ untuk menunjukkan apakah semua variabel independen atau variabel bebas yang dimasukkan dalam model mempunyai pengaruh secara bersama-sama terhadap variabel dependen/terikat (Ghozali, 2009 ).

\section{HASIL DAN PEMBAHASAN}

Data yang dikumpulkan dari responden dengan jumlah kelas jawaban ( $k$ ) sebanyak 5 yaitu sangat setuju, setuju, netral, tidak setuju, dan sangat tidak setuju dan range $(r)=5-1=4$, menghasilkan interval kelas (i) sebesar 0,80. Sehingga skala hasil interprestasi rata-rata responden adalah :

Tabel 1. Hasil Interprestasi Rata-Rata Responden

\begin{tabular}{ccl}
\hline Skala Data & Kelas & Kategori \\
\hline 1 & $1,00-1,79$ & Sangat Rendah \\
\hline 2 & $1,80-2,59$ & Rendah \\
\hline 3 & $2,60-3,39$ & Cukup \\
\hline 4 & $3,40-4,19$ & Tinggi \\
\hline 5 & $4,20-5,00$ & Sangat Tinggi \\
\hline
\end{tabular}

Sumber: Daya yang Diolah (2020)

Berdasarkan hasil penelitian yang dilakukan dapat dianalisa secara deskriptif sebagai berikut: 
Tabel 2. Persepsi wisatawan pada daya tarik obyek wisata dari segi fisik:

\begin{tabular}{|c|c|c|c|}
\hline Indikator & $\begin{array}{l}\text { Rata- } \\
\text { rata }\end{array}$ & Kategori & $\begin{array}{l}\text { Total } \\
\text { Skor } \\
\text { Rata- } \\
\text { rata }\end{array}$ \\
\hline $\begin{array}{l}\text { Tempat parkir yang } \\
\text { luas dan memadai }\end{array}$ & 3,87 & Tinggi & \multirow{5}{*}{3,48} \\
\hline $\begin{array}{l}\text { Tersedia penjual } \\
\text { minuman dan } \\
\text { makanan }\end{array}$ & 3,82 & Tinggi & \\
\hline $\begin{array}{l}\text { Tersedia tempat } \\
\text { sampah yang mudah } \\
\text { ditemukan }\end{array}$ & 3,16 & Cukup & \\
\hline $\begin{array}{l}\text { Terdapat tempat } \\
\text { istirahat yang } \\
\text { memadai }\end{array}$ & 3,56 & Tinggi & \\
\hline $\begin{array}{l}\text { Mudah ditemukan } \\
\text { toilet yang bersih }\end{array}$ & 2,96 & Cukup & \\
\hline
\end{tabular}

Tabel di atas menunjukkan bahwa variabel persepsi wisatawan pada objek wisata dari segi fisik termasuk kategori tinggi yaitu 3,48 artinya semakin tinggi penilaian wisatawan maka objek wisata Pantai Baru dikatakan sebagai pantai yang baik dan layak untuk dikunjungi wisatawan.

Tabel 3. Persepsi wisatawan pada daya tarik obyek wisata dari segi non fisik:

\begin{tabular}{|c|c|c|c|}
\hline Indikator & $\begin{array}{l}\text { Rata- } \\
\text { rata }\end{array}$ & Kategori & $\begin{array}{l}\text { Total } \\
\text { Skor } \\
\text { Rata- } \\
\text { rata }\end{array}$ \\
\hline $\begin{array}{l}\text { Memiliki keunikan } \\
\text { tersendiri }\end{array}$ & 4,42 & $\begin{array}{l}\text { Sangat } \\
\text { Tinggi }\end{array}$ & \multirow{5}{*}{3,92} \\
\hline $\begin{array}{l}\text { Kondisi baik dan } \\
\text { layak dikunjungi }\end{array}$ & 3,82 & Tinggi & \\
\hline $\begin{array}{l}\text { Memiliki keindahan } \\
\text { disetiap sudutnya }\end{array}$ & 4,04 & Tinggi & \\
\hline $\begin{array}{l}\text { Nyaman untuk } \\
\text { dikunjungi }\end{array}$ & 4,09 & Tinggi & \\
\hline $\begin{array}{l}\text { Tingkat keamanan } \\
\text { yang baik }\end{array}$ & 3,24 & Cukup & \\
\hline
\end{tabular}

Persepsi wisatawan pada objek wisata dari segi non fisik mempunyai total skor ratarata sebesar 3,92. Hal ini memperlihatkan bahwa variabel persepsi wisatawan pada daya tarik objek wisata dari segi non fisik adalah tinggi.
Tabel 4. Motivasi yang mendorong:

\begin{tabular}{|c|c|c|c|}
\hline Indikator & $\begin{array}{l}\text { Rata- } \\
\text { rata }\end{array}$ & Kategori & $\begin{array}{l}\text { Total } \\
\text { Skor } \\
\text { Rata- } \\
\text { rata }\end{array}$ \\
\hline $\begin{array}{l}\text { Mencari sesuatu } \\
\text { yang menarik dan } \\
\text { baru }\end{array}$ & 3,81 & Tinggi & \multirow{5}{*}{3,94} \\
\hline $\begin{array}{l}\text { Bertemu dengan } \\
\text { orang-orang baru }\end{array}$ & 3,40 & Tinggi & \\
\hline $\begin{array}{l}\text { Melepaskan diri dari } \\
\text { rutinitas sehari-hari }\end{array}$ & 4,14 & Tinggi & \\
\hline $\begin{array}{l}\text { Menikmati } \\
\text { pemandangan alam } \\
\text { dan mencari } \\
\text { petualangan }\end{array}$ & 4,33 & $\begin{array}{l}\text { Sangat } \\
\text { Tinggi }\end{array}$ & \\
\hline $\begin{array}{l}\text { Menghabiskan waktu } \\
\text { dengan pasangan, } \\
\text { keluarga, dan teman }\end{array}$ & 4,01 & Tinggi & \\
\hline
\end{tabular}

Sumber: Data Primer yang Diolah (2020)

Variabel motivasi yang mendorong mempunyai rata-rata skor responden sebesar 3,94 yang menunjukkan motivasi ini tergolong kategori yang tinggi. Menikmati pemandangan alam dan mencari petualangan merupakan motivasi yang mendorong paling tinggi.

Tabel 5. Motivasi yang menarik:

\begin{tabular}{|c|c|c|c|}
\hline Indikator & $\begin{array}{l}\text { Rata- } \\
\text { rata }\end{array}$ & Kategori & $\begin{array}{l}\text { Total } \\
\text { Skor } \\
\text { Rata- } \\
\text { rata }\end{array}$ \\
\hline $\begin{array}{l}\text { Harga tiket yang } \\
\text { Terjangkau }\end{array}$ & 3,81 & Tinggi & \multirow{5}{*}{3,60} \\
\hline $\begin{array}{l}\text { Mempelajari sejarah, } \\
\text { budaya, seni dan } \\
\text { tradisi }\end{array}$ & 2,97 & Cukup & \\
\hline $\begin{array}{l}\text { Menikmati sumber } \\
\text { daya alam }\end{array}$ & 4,05 & Tinggi & \\
\hline $\begin{array}{l}\text { Mempunyai imej } \\
\text { positif sebagai } \\
\text { tempat wisata }\end{array}$ & 2,88 & Tinggi & \\
\hline $\begin{array}{l}\text { Lokasi tempat wisata } \\
\text { dekat tempat tinggal }\end{array}$ & 4,28 & $\begin{array}{l}\text { Sangat } \\
\text { Tinggi }\end{array}$ & \\
\hline
\end{tabular}

Motivasi untuk menarik mempunyai nilai rata-rata skor responden sebesar 3,60 yang berarti motivasi yang menarik adalah tinggi, dengan nilai tertinggi pada lokasi objek wisata yang dekat dengan tempat tinggalnya. 
Tabel 6. Motivasi intrinsik:

\begin{tabular}{|c|c|c|c|}
\hline Indikator & $\begin{array}{l}\text { Rata } \\
\text {-rata }\end{array}$ & Kategori & $\begin{array}{l}\text { Total } \\
\text { Skor } \\
\text { Rata } \\
\text {-rata }\end{array}$ \\
\hline $\begin{array}{l}\text { Untuk mencari } \\
\text { kenyamanan }\end{array}$ & 4,08 & Tinggi & \multirow{5}{*}{3,97} \\
\hline $\begin{array}{l}\text { Untuk } \\
\text { bersantai }\end{array}$ & 4,18 & Tinggi & \\
\hline $\begin{array}{l}\text { Karena suka } \\
\text { berenang di } \\
\text { pantai }\end{array}$ & 3,52 & Tinggi & \\
\hline $\begin{array}{l}\text { Mencari } \\
\text { tempat wisata } \\
\text { yang baru }\end{array}$ & 4,28 & $\begin{array}{l}\text { Sangat } \\
\text { Tinggi }\end{array}$ & \\
\hline $\begin{array}{l}\text { Sebagai } \\
\text { hiburan }\end{array}$ & 3,85 & Tinggi & \\
\hline
\end{tabular}

Sumber: Data Primer yang Diolah (2020)

Variabel motivasi intrinsik mempunyai ratarata skor sebesar 3,97 artinya bahwa motivasi intrinsik termasuk kategori yang tinggi dengan skor tertinggi pada motivasi mencari tempat wisata yang baru.

Tabel 7. Motivasi ekstrinsik:

\begin{tabular}{lccc}
\hline \multicolumn{1}{c}{ Indikator } & $\begin{array}{l}\text { Rata- } \\
\text { rata }\end{array}$ & Kategori & $\begin{array}{l}\text { Total } \\
\text { Skor } \\
\text { Rata- } \\
\text { rata }\end{array}$ \\
\cline { 1 - 2 } $\begin{array}{l}\text { Untuk melakukan } \\
\text { penelitian }\end{array}$ & 2,90 & Cukup & \\
$\begin{array}{l}\text { Untuk kegiatan } \\
\text { sekolah }\end{array}$ & 3,34 & Cukup & \\
\hline Sumber: & & & \\
\hline
\end{tabular}

Sumber: Data Primer yang Diolah (2020)

Rata-rata skor responden variabel motivasi ekstrinsik sebesar 3,12 yang artinya motivasi ekstrinsik hanya tergolong kategori cukup.

Tabel 8. Minat Kunjung Ulang:

\begin{tabular}{|c|c|c|c|}
\hline Indikator & $\begin{array}{l}\text { Rata- } \\
\text { rata }\end{array}$ & Kategori & $\begin{array}{l}\text { Total } \\
\text { Skor } \\
\text { Rata- } \\
\text { rata }\end{array}$ \\
\hline $\begin{array}{l}\text { Karena mendapat } \\
\text { informasi terbaru } \\
\text { tentang Pantai Baru } \\
\text { Bantul }\end{array}$ & 3,95 & Tinggi & \multirow{3}{*}{4,03} \\
\hline $\begin{array}{l}\text { Dengan mengajak } \\
\text { keluarga/teman } \\
\text { untuk melihat } \\
\text { Pantai Baru }\end{array}$ & 4,21 & $\begin{array}{l}\text { Sangat } \\
\text { Tinggi }\end{array}$ & \\
\hline $\begin{array}{l}\text { Untuk bernostalgia } \\
\text { di Pantai Baru } \\
\text { Bantul }\end{array}$ & 3,92 & Tinggi & \\
\hline
\end{tabular}

Sumber: Data Primer yang Diolah (2020)
Total skor rata-rata responden pada variabel minat kunjung ulang adalah 4,03. Hal ini memperlihatkan bahwa minat untuk berkunjung ulang di Pantai Baru adalah tinggi, dengan nilai tertinggi pada alasan untuk mengajak keluarga/teman melihat pantai tersebut.

Berdasarkan hasil uji normalitas dengan uji Sample Kolomogorow Smirnov diketahui nilai Asymp. Sig. (2-tailed) adalah 0,200 atau probabilitas lebih besar dari 0,05 maka dikatakan bahwa data penelitian berdistribusi normal. Dari hasil uji heteroskedastisitas dengan menggunakan uji glejser didapatkan nilai probabilitas signifikasi variabel persepsi wisatawan pada daya tarik objek wisata adalah 0,806 $>0,05$ dan variabel motivasi wisatawan adalah $0,381>0,05$. Sehingga dapat dikatakan bahwa model regresi tidak terkandung heteroskedastisitas. Dari hasil perhitungan uji multikolinieritas diketahui nilai tolerance $X_{1}$ (persepsi wisatawan) sebesar $0,758>0,10$ dan $X_{2}$ (motivasi wisatawan) sebesar $0,758>0,10$ artinya tidak terdapat korelasi antar variabel bebas (independen) yang bernilai lebih dari 95\%. Berdasarkan hasil hitung nilai variance inflation factor (VIF) memperlihatkan hal yang sama bahwa tidak terdapat satu variabel independen yang mempunyai nilai lebih dari 10. Nilai VIF untuk $X_{1}$ (persepsi wisatawan) $1,320<10$ dan $\mathrm{X}_{2}$ (motivasi wisatawan) $1,320<10$. Sehingga dapat disimpulkan bahwa diantara variabel bebas yang ada tidak terjadi masalah multikorelasi artinya diantara variabel bebas tidak terjadi multikorelasi . Dengan tingkat kepercayaan $95 \%$, derajad kebebasan (df1) $=\mathrm{k}=1$, dan $\mathrm{df} 2=\mathrm{n}-\mathrm{k}=100-2=98$ diperoleh nilai Ftabel $=3,09$.

Dari hasil perhitungan regresi berganda didapatkan nilai koefisien konstanta sebesar 1,058 , koefisien regresi persepsi wisatawan $\left(\mathrm{X}_{1}\right)$ sebesar 0,073 dan koefisien regresi motivasi wisatawan $\left(X_{2}\right)$ sebesar 0,121. Berdasarkan perhitungan tersebut, dapat dirumuskan persamaan regresinya adalah $Y=1,058+0,073 X_{1}+$ $0,121 X_{2}$

Berdasarkan hasil uji $F$ memperlihatkan bahwa secara bersamasama antara persepsi dan motivasi berpengaruh terhadap minat kunjung ulang, karena nilai $F$ yang diperoleh adalah 
sebesar 40,890 dengan taraf signifikansi 0,000 dimana nilai sigifikan yang diperoleh kurang dari 0,05 . Sehingga memperlihatkan bahwa secara signifikan variabel minat kunjung ulang dapat dijelaskan oleh variabel persepsi dan motivasi. Artinya, secara signifikan dapat disimpulkan bahwa minat kunjung ulang dipengaruhi baik oleh variabel persepsi wisatawan terhadap objek wisata dan faktor motivasi wisatawan untuk bekunjung lagi di Pantai Baru.

Persepsi merupakan proses yang timbul sebagai akibat dari sensasi yaitu aktivitas perasaan atau penyebab keadaan emosi yang menggembirakan dan motivasi merupakan dorongan yang timbul dari seorang konsumen berpengaruh terhadap proses pengambilan keputusan dalam pembelian dan penggunaan barang dan jasa, sehingga kedua variabel ini mempengaruhi seseorang dalam mengambil keputusan untuk melakukan perjalanan wisata. Dorongan yang muncul karena keinginan untuk merasakan dan melihat suatu objek akan menimbulkan ketertarikan (minat) pada setiap wisatawan. Berdasarkan minat tersebut, apabila wisatawan merasakan puas maka mereka akan melakukan kunjungan ulang.

Berdasarkan hasil uji t diperoleh thitung pada variabel persepsi wisatawan pada obyek wisata $\left(X_{1}\right)$ sebesar 2,647 dengan nilai positif dan lebih besar dari 1,6606 (thitung > ttabel). Hal ini memperlihatkan bahwa $\mathrm{H} 1$ diterima, artinya ada pengaruh yang positif antara persepsi wisatawan tentang daya tarik objek wisata terhadap minat untuk berkunjung ulang ke Pantai Baru Yogyakarta. Semakin baik penilaian wisatawan maka akan semakin besar pula minat wisatawan untuk berkunjung kembali, sebaliknya jika wisatawan mempunyai penilaian yang buruk maka jumlah pengunjung akan semakin berkurang. Dari hasil perhitungan uji t untuk thitung pada variabel motivasi wisatawan $\left(\mathrm{X}_{2}\right)$ sebesar 6,223 dengan nilai positif yan dan lebih besar dari 1,6608 (thitung > ttabel), sehingga $\mathrm{H} 1$ diterima, artinya ada pengaruh positif antara motivasi wisatawan terhadap minat wisatawan tersebut untuk melakukan kunjung ulang di Pantai Baru. Semakin tinggi motivasi wisatawan maka semakin tinggi pula minat mereka untuk berkunjung kembali, sebaliknya semakin kecil motivasinya untuk berwisata maka semakin rendah pula minat wisatawan untuk melakukan kunjungan ulang.

\section{PENUTUP}

Secara bersama-sama persepsi wisatawan terhadap daya tarik objek wisata dan motivasi wisatawan mempunyai pengaruh terhadap minat kunjung ulang ke Pantai Baru Yogyakarta. Semakin besar persepsi wisatawan pada daya tarik objek wisata dan motivasi wisatawan dalam berkunjung ke Pantai Baru, maka semakin besar juga minat wisatawan untuk melakukan kunjung ulang. Secara parsial persepsi wisatawan pada daya tarik objek wisata mempunyai pengaruh positif terhadap minat wisatawan untuk melakukan kunjung ulang, artinya semakin baik persepsi wisatawan pada obyek wisata Pantai Baru, akan mengakibatkan semakin besar pula minat wisatawan melakukan kunjung ulang. Faktor motivasi wisatawan juga mempunyai pengaruh yang positif terhadap minat kunjung ulang wisatawan, yang berarti semakin tinggi motivasi wisatawan untuk berkunjung maka akan semakin besar pula minat wisatawan untuk mengunjungi lahi di Pantai Baru. Penelitian ini masih terdapat kelemahan karena variabel yang digunakan hanya terbatas pada persepsi terhadap daya tarik objek wisata dan motivasi wisatawan saja, sehingga perlu pengkajian lebih mendalam dengan menambah variabel lain yang mempengaruhi minat kunjung ulang wisatawan.

\section{DAFTAR PUTAKA}

Ghozali, Imam. (2009). Aplikasi Analisis Multivariate Dengan Program SPSS. Semarang: BP UNDIP

Hayati, (2013). "Faktor-faktor Yang Mempengaruhi Motivasi Wistawan Berkunjung ke Candi Muara Takus Kec. XIII Koto Kampar Kabupaten Kampar No. 5". Repository Universitas Riau. 1-15 http://repository.unri.ac.id:80/handle/12 $3456789 / 4409$ 
I Gusti. (2016). Geografi Pariwisata dan Ekonomi Kreatif, Jakarta: PT Raja Grafindo Persada

Mill, Robert $\mathrm{C}$ and Morrison Alastair M. (1985). The Tourism System, An Introductory Text, New Jersey: Prentice Hall Inc.

Nuraeni, Sofia. (2014). Analisis FaktorFaktor Yang Mempengaruhi Minat Kunjungan Ulang Wisatawan Semarang. Jurnal Bisnis Strategi. Volume 23 No.1. 1-20

Pitana, I Gede dan Putu G. Gayatri, (2005), Sosiologi Pariwisata, Yogyakarta: Penerbit Andi

Sangaji, Etta Mamang, dan Sopiah. (2013). Perilaku Konsumen, Yogyakarta: CV Andi Offset

Statistik Kepariwisataan 2019. (2020). Dinas Pariwisata Daerah Istimewa Yogyakarta.

Umar, Husein. (2003), Riset Pemasaran dan Perilaku Konsumen. Jakarta: Gramedia Pustaka Utama

Undang-Undang Republik Indonesia No. 10 Tahun 2009 Tentang Kepariwisataan

Witarsana. (2017). Motivasi dan Persepsi Wisatawan Mancanegara Berwisata Alam Trekking di Taman Wisata Alam Gunung Batur Bukit Payang. Jurnal IPTA Vol. 5 No. 1. 13-19

Zaenuri. (2012). Perencanaan Strategis Kepariwisataan Daeran: Konsep dan Aplikasi. Jogjakarta: e-Gov Publising 